\title{
SINERGISITAS UNSUR MASYARAKAT DAN PEMERINTAH LOKAL DI KELURAHAN AIR TAWAR BARAT KOTA PADANG SEBAGAI UPAYA PENINGKATAN KAPASITAS WARGA MENGHADAPI ANCAMAN BENCANA GEMPA DAN TSUNAMI
}

\author{
Rafki Imani' ${ }^{1)}$, Utami Dewi Arman ${ }^{2)}$, Afrilda Sari ${ }^{3)}$ \\ ${ }^{1}$ Fakultas Teknik Universitas Putra Indonesia "YPTK" Padang, Jl. Raya Lubuk Begalung Kota Padang Sumatera \\ Barat \\ email: rafimani17@yahoo.co.id \\ ${ }^{2}$ Fakultas Teknik Universitas Putra Indonesia "YPTK” Padang, Jl. Raya Lubuk Begalung Kota Padang Sumatera \\ Barat \\ email: udewi2679@gmail.com \\ ${ }^{3}$ Fakultas Teknik Universitas Putra Indonesia "YPTK" Padang, Jl. Raya Lubuk Begalung Kota Padang Sumatera \\ Barat \\ email: afrildasari@yahoo.com
}

\begin{abstract}
Abstrak
Kota Padang merupakan wilayah yang rentan terhadap ancaman bencana gempa dan tsunami. Bencana gempa yang mampu menimbulkan risiko tsunami tidak dapat diprediksi kapan terjadinya. Kondisi ini menuntut semua lapisan masyarakat harus memiliki pengetahuan terhadap kemungkinan bencana itu, agar memiliki kapasitas menghadapi ancaman gempa-tsunami. Penelitian ini bertujuan untuk mengevaluasi sinergisitas warga dan pemerintah lokal untuk meningkatkan kapasitas warga dalam menghadapi ancaman gempa dan tsunami di Kelurahan Air Tawar Barat Kota Padang. Penelitian ini adalah penelitian deskriptif-kuantitatif dengan data primer yang dikumpulkan berdasarkan wawancara mendalam dengan responden dan penyebaran kuesioner tentang pengetahuan bahaya gempa dan tsunami. Data Sekunder dikumpulkan dari data-data yang ada di kantor kelurahan dan kelompok KSB, dari buku-buku dan jurnal terkait serta dari internet. Hasil penelitian menjelaskan bahwa sebagian besar warga telah memiliki kapasitas terhadap ancaman tsunami, namun belum mampu menjalin komunikasi dan koordinasi yang baik dengan pemerintah lokal yang ada di lokasi penelitian. Berdasarkan hal ini perlu ditingkatkan komunikasi dan koordinasi yang baik dan lancar antara warga dan instansi lokal di sana.
\end{abstract}

Keywords: Gempa, tsunami, kapasitas masyarakat, Kelurahan Air Tawar Barat Kota Padang.

\section{PENDAHULUAN}

Kota Padang Sumatera Barat termasuk salah satu daerah yang rentan bencana [1], termasuk ancaman gempa-tsunami karena letaknya yang langsung dipengaruhi oleh lempeng Eurasia dan Indo-Australia yang terus bergerak membentuk zona subduksi [2]. Zona subduksi inilah yang selama ini menjadi sumber gempa besar di Sumatera Barat, seperti yang ditampilkan oleh Gambar 1 [3]. Beberapa kejadian gempa yang diikuti tsunami yang pernah terjadi di sekitar wilayah Kota Padang adalah; tsunami Banggai (2000), tsunami Aceh tahun 2004 [4], tsunami Bengkulu (2007), dan tsunami Mentawai (2010). Selama kejadian tsunami itu, telah tercatat sebanyak 170 ribu orang meninggal dunia akibat tsunami [5].

Bencana tsunami terjadi akibat adanya peristiwa gempabumi di dasar laut dengan pergerakan vertikal yang sangat besar dari dua lempeng besar bumi [6]. Kejadian tsunami berlangsung pada jarak yang sangat berdekatan sekali setelah terjadinya gempabumi di dasar laut, sehingga banyak warga yang kurang respon terhadap bencana tsunami ini [7]. Sejak gempa dan tsunami yang terjadi di Sumatera Andaman-Aceh pada tahun 2004 dan gempa Yogyakarta dan Jawa Tengah 2006, Indonesia khususnya Sumatera Barat, telah menjadi perhatian dunia internasional dalam hal kebencanaan [8]. Setelah peristiwa 
itu, segala upaya pengurangan risiko bencana semakin gencar dilakukan hingga pemerintah mengeluarkan undang-undang kebencanaan yaitu Undang-undang Nomor 24 Tahun 2007 tentang Penanggulangan Bencana. Dalam undangundang tersebut dinyatakan bahwa usaha penanggulangan bencana bertujuan untuk melindungi masyarakat dari ancaman bencana [9].

Dari sejarah bencana tsunami yang pernah melanda wilayah Sumatera Barat, perlu dilakukan suatu upaya yang berkelanjutan dalam penanggulangan bencana gempa dan tsunami. Bencana gempa dan tsunami dapat terjadi kapan saja jika sumber gempanya terjadi di zona subduksi [10]. Gempa juga tidak dapat diprediksi kapan terjadinya, namun peringatan dini dari ancaman tsunami bisa diupayakan jika sudah mengetahui sumber gempanya. Karakteristik ancaman tsunami tersebut harus dikenali dan diketahui secara baik. Upaya ini tidak dapat dilakukan secara sporadis oleh pihak-pihak yang terkait, namun harus dilakukan secara bersama, baik oleh pemerintah pusat, pemerintah daerah maupun oleh warga.

Pengurangan risiko bencana (PRB) harus sudah diterapkan pada masa tidak terdapat bencana. Hal ini dilakukan supaya segala persiapan dapat ditempuh sebaik mungkin. Menurut Anam (2018), ada tiga filosofi penanganan bencana yang harus dipahami oleh masyarakat. Pertama, menjauhkan bencana dari warga, kedua, warga dijauhkan dari ancaman bencana, dan ketiga, hidup berdampingan secara harmonis dengan bencana [11] Cara pertama dan kedua seperti sangat sulit untuk dipisahkan dari warga, sehingga pilihan dilakukan dengan cara ketiga yakni, hidup berdampingan dengan bencana namun terus mengembangkan pengetahuan, kesiapsiagaan, kapasitas atau kemampuan menangani bencana serta selalu mengembangkan kearifan lokal. Peningkatan kapasitas melalui cara ketiga ini menjadi sangat mungkin dilakukan dalam rangka penanggulangan bencana. Pelibatan masyarakat dalam mendukung dan menjalankan sendiri prosedur mitigasi bencana sangat berdampak terhadap pengurangan risiko bencana, baik pada situasi sebelum bencana, saat darurat bahkan setelah bencana terjadi [12].

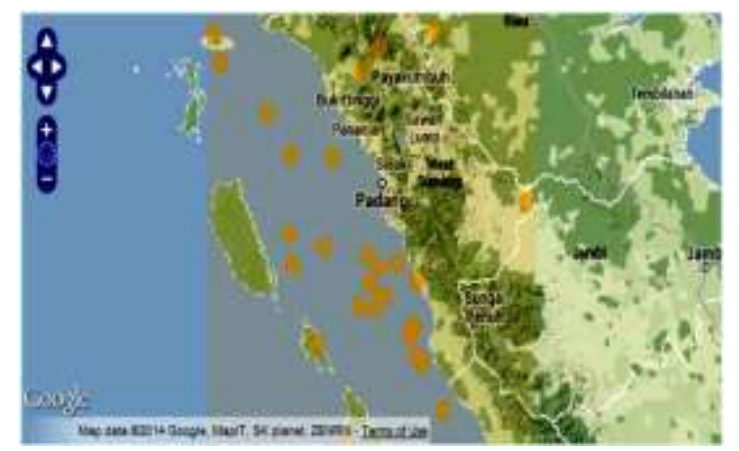

Gambar 1. Gempa-gempa di zona subduksi yang menjadi penyebab tsunami di wilayah Sumatera Barat [13].

Keterlibatan unsur masyarakat dan berbagai institusi lokal yang ada di daerah rawan bencana tidak dapat dipisahkan, melihat penanggulangan bencana tidak dapat dilakukan hanya dengan tindakan teknis saja. Banyak hal dan unsur-unsur lain yang perlu dipertimbangkan, karena koordinasi yang tepat sasaran biasanya akan lebih berjalan dengan baik antara institusi lokal dan warga sekitar daerah yang rentan. Melihat pentingnya kedua unsur tersebut, maka peningkatan kapasitas dan kesiapan warga haruslah menjadi prioritas utama dalam penanggulangan bencana, sehingga paradigma penanggulangan bencana yang semula dianggap hanya dilakukan saat darurat saja, dapat bergeser ke arah pencegahan dan kesiapsiagaan. Upaya ini sangat berguna dalam mendukung pemerintah melakukan penanggulangan bencana di Indonesia.

Penguatan unsur warga dan institusi lokal ini harus didukung penuh oleh pemerintah, sebab pada level ini jarang sekali mendapat 
perhatian khusus, padahal unsur di level ini mampu menjangkau dan memahami keinginan masyarakat lokal, sehingga komunikasi dan koordinasi berjalan dengan lebih baik, yang selama ini menjadi syarat tercapainya penanggulangan bencana dengan lebih baik. Berdasarkan hal-hal di atas, maka dalam penelitian ini diarahkan untuk mengevaluasi sinergisitas warga dan pemerintah lokal, agar warga memiliki kapasitas dalam menghadapi ancaman bencana gempa dan tsunami. Penelitian ini mengambil contoh kasus di Kelurahan Air Tawar Barat, Kota Padang, Sumatera Barat.

Saat ini, masyarakat di daerah tersebut telah membentuk komunitas peduli bencana, yang dinamakan dengan Kelompok Siaga Bencana (KSB). Bagi masyarakat setempat, kelompok KSB ini sangat membantu masyarakat dalam hal penanggulangan bencana, namun terkadang karena kesibukan masingmasing anggotanya, upaya dan program yang dijalankan oleh kelompok KSB sering terkendala dan tidak berkesinambungan. Oleh sebab itu, agar upaya mitigasi bencana dalam peningkatan kapasitas masyarakat ini dapat berhasil, maka mulai dari struktural/institusi lokal yang ada, dalam hal ini kelurahan hingga semua warga termasuk kelompok-kelompok siaga bencana, harus saling bekerjasama dan masing-masing harus terlibat satu sama lain.

\section{METODE PENELITIAN}

Metode Penelitian ini merupakan penelitian kuantitatif dengan analisa deskriptif-kualitatif yang dilakukan di Kelurahan Air Tawar Barat, Padang Utara, Kota Padang, Sumatera Barat. Pemilihan lokasi penelitian ini karena berada berhadapan langsung dengan pantai Padang, dimana di daerah tersebut merupakan sumber gempa subduksi yang selama ini sering melanda wilayah Kota Padang. Sebagian masyarakat di sana mempunyai mata pencarian sebagai nelayan dan di daerah tersebut juga banyak bangunan sekolah dan padat pemukiman, sehingga dapat meningkatkan risiko terdampak ancaman bencana tsunami.

Data primer yang dibutuhkan diperoleh dengan melakukan survei langsung ke lapangan untuk melihat sarana dan prasarana yang ada disana sebagai fasilitas mitigasi bencana. Kemudian melakukan wawancara mendalam terhadap warga untuk mengevaluasi gambaran sikap dan pengetahuan yang dimiliki warga tentang bencana gempatsunami dengan cara menyebar kuesioner. Sedangkan data lain yang dibutuhkan berupa data sekunder, diperoleh dari data-data terkait yang ada di kantor kelurahan maupun sumber bacaan dari artikel dan buku-buku terkait serta dari internet.

Teknik analisis data dilakukan dengan metode deskriptif-kualitatif. Data-data yang telah dikumpulkan diidentifikasi agar dapat diintepretasikan, yang bertujuan untuk mengetahui sejauh mana pengetahuan, sikap, kesiapan baik fisik maupun non-fisik, serta dan sinergisitas warga dengan institusi lokal dalam menghadapi ancaman tsunami setelah gempa terjadi, sehingga dengan begitu warga memiliki kesiapan yang baik di masa mendatang terhadap risiko terjadinya tsunami.

\section{HASIL DAN PEMBAHASAN}

Kelompok Siaga Bencana (KSB) yang ada di Kelurahan Air Tawar Barat, Kecamatan Padang Utara, Kota Padang, dipilih sebagi target awal karena memiliki data yang lengkap tentang informasi kebencanaan, yang dapat memudahkan dalam mengumpulkan informasi bencana tsunami sebagai data penelitian.

$40 \begin{gathered}\text { Penyebaran kuesioner dilakukan terhadap } \\ \text { responden (warga) dengan }\end{gathered}$ mempertimbangkan jenis kelamin, usia, dan tingkat pendidikan (perhatikan Gambar 2, Gambar 3 dan Tabel 1). Pertimbangan kategori ini ditetapkan dengan tujuan untuk mengetahui 
sejauh mana pengetahuan dan pemahaman responden terhadap informasi bencana tsunami.

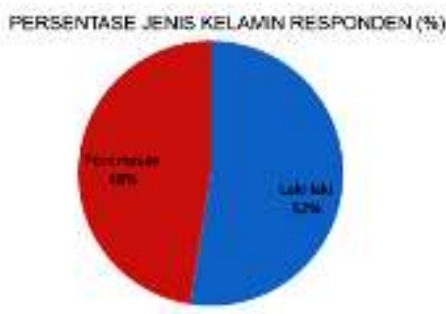

Gambar 2. Persentase jenis kelmin responden.

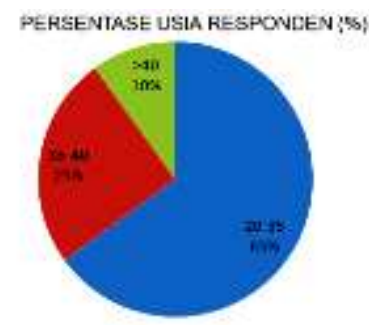

Gambar 3. Persentase usia responden.

Berdasarkan Gambar 2 dan 3 di atas, sebanyak 40 responden terdapat $52 \%$ laki-laki dan $48 \%$ perempuan. Sedangkan berdasarkan usia terdapat $65 \%$ berusia sekitar 20-35 tahun, $25 \%$ berusia 36 - 40 tahun dan $10 \%$ berusia di atas 40 tahun. Responden berdasarkan tingkat pendidikan, terdapat berpendidikan SMA atau sederajat sebanyak 14 orang, yang berpendidikan D3 sebanyak 1 orang, serta responden yang berpendidikan $\mathrm{S} 1$ sebanyak 25 orang, seperti Tabel 1. Mayoritas tingkat pendidikan responden yang dijadikan sampel dalam penelitian ini adalah yang berpendidikan SMA atau sederajat.

Tabel 1. Tingkat pendidikan responden.

\begin{tabular}{ccc}
\hline Pendidikan & Frekuensi & Persentase $(\%)$ \\
\hline SMA/Sederajat & 14 & $35 \%$ \\
D3 & 1 & $2,5 \%$ \\
S1 & 25 & $62,5 \%$ \\
S2 & 0 & $0 \%$ \\
S3 & 0 & $0 \%$ \\
Total & 40 & $100 \%$ \\
\hline
\end{tabular}

Analisa data telah dilakukan dengan teknik deskriptif-kualitatif, melalui beberapa alternatif pertanyaan yang diajukan kepada responden melalui kuesioner, yang bertujuan untuk mendapatkan hasil evaluasi yang diinginkan. Gambar 4 adalah sistematika alur alternatif pertanyaan dari kuesioner.

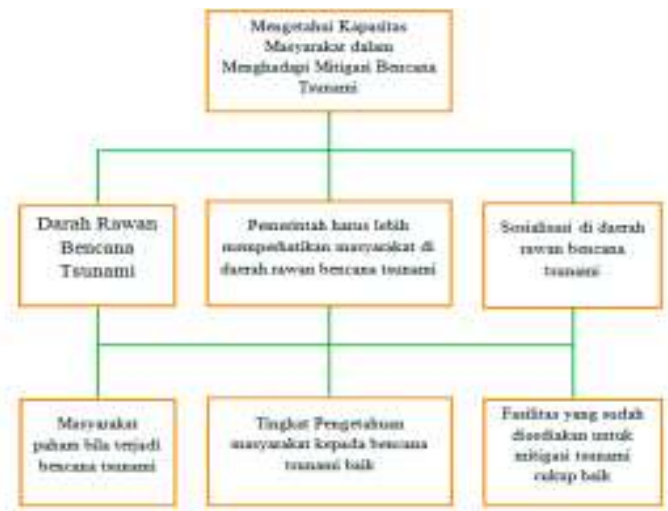

Gambar 4. Bagan hirarki alternatif pertanyaan berdasarkan AHP.

Survei dimulai dengan mendatangi instansi terkait seperti kantor kelurahan, lalu menemui warga yang akan diwawancarai dan diberikan kuesioner, yang telah ditentukan berdasarkan kategori yang sudah ditetapkan. Selanjutnya, penulis mendatangi Kelompok Siaga Bencana (KSB) yang ada di lokasi penelitian. KSB ini sangat membantu dalam penyebaran informasi kebencanaan, dan sudah banyak memberikan penyuluhan kepada warga sekitar kelurahan, serta juga telah melakukan simulasi tsunami. Beberapa warga yang sering mendapat penyuluhan dari KSB adalah, seperti ibu-ibu rumah tangga dan nelayan. Survei juga penulis lakukan untuk melihat kesiapan sekolahsekolah yang ada di daerah tersebut, dimana lokasi sekolah sangat dekat dengan pantai.

Dari hasil wawancara dengan pihak KSB diperoleh bahwa semua sekolah-sekolah yang ada di sana sudah diberikan simulasi kebencanaan tsunami, mulai dari apa saja yang akan dilakukan pada saat gempa datang, apa saja yang dilakukan apabila gempa cukup lama bergetar dan berisiko tsunami, serta simulasi jalur evakuasi juga sudah dilakukan oleh organisasi KSB ini terhadap sekolahsekolah yang berada di lingkungan tersebut. 
Pada dasarnya, perhatian institusi lokal (dalam hal ini kelurahan) sebetulnya sudah cukup baik dalam memberikan pengetahuan dan informasi kebencanaan, namun kendala komunikasi terkadang menjadi penghalang kelancaran mitigasi di sana. Pada saat wawancara dilakukan dengan ketua kelompok KSB di sana, dijelaskan bahwa warga di Kelurahan Air Tawar Barat cukup banyak yang tidak merespon dengan baik setiap sosialisasi yang diadakan, dan terkesan tidak peduli dengan upaya yang dilakukan oleh KSB, bahkan ada yang beranggapan bahwa keberadaan kelompok KSB seolah menakuti warga akan bahaya tsunami, sehingga tidak semua warga yang bisa menerima dengan baik setiap upaya penyuluhan dan sosialisasi yang diberikan.

Sementara di lain pihak, ada beberapa warga yang mengaku bahwa kelurahan melalui KSB belum pernah memberikan penyuluhan tentang bencana tsunami. Pernyataan ini tentunya menjelaskan bahwa antara warga dan institusi lokal/kelurahan tidak terjalin sinergisitas dan komunikasi yang baik dalam penanggulan kebencanaan, sehingga apa yang diharapkan bersama menjadi tidak tercapai.

Dalam penelitian ini juga disebarkan kuesioner untuk mengetahui kesiapan warga dalam menghadapi tsunami di Kelurahan Air Tawar Barat ini. Kuesioner disebarkan dengan mendatangi rumah warga yang sudah ditentukan sebelumnya sebagai responden utama berdasarkan usia, jenis kelamin dan pendidikan, serta dipilih juga berdasarkan tempat tinggal warga yang berhadapan langsung dengan laut.

Kuesioner disebarkan kepada 40 responden dengan 40 pertanyaan seputar pengetahuan dan kesiapsiagaan warga akan kemungkinan terjadinya bencana tsunami. Data yang sudah dikumpulkan dari kuesioner itu kemudian dianalisis dengan teknik deskriptif-kualitatif. Semua pertanyaan beserta jawaban dari responden dikumpulkan lalu dirangking mulai dari jawaban terbanyak hingga jawaban yang paling sedikit. Jawaban yang terbanyak akan diambil sebagai jawaban terbaik dan dijadikan sebagai jawaban atas sikap dan pengetahuan warga tentang risiko bencana tsunami di daerah penelitian.

Berdasarkan hasil analisa, diperoleh bahwa warga di lokasi penelitian ini sebagian besar sudah memiliki sikap dan kapasitas tinggi terhadap bencana tsunami, terbukti bahwa warga di sana sebenarnya sudah cukup baik akan kebencanaan. Sementara itu, dari segi pengetahuan disimpulkan bahwa warga masih belum mampu berkoordinasi secara baik dengan instansi lokal dan belum memiliki komunikasi yang lancar dengan instansi lokal tersebut, sehingga informasi kebencanaan terkadang sering terhambat sampai ke warga.

\section{KESIMPULAN}

Berdasarkan hasil penelitian disimpulkan bahwa sebagian besar warga di Kelurahan Air Tawar Barat Kota Padang telah memiliki sikap dan kapasitas yang baik dalam menghadapi risiko gempa-tsunami. Namun sinergisitas antara warga dan instansi lokal di sana belum memiliki koordinasi dan komunikasi yang baik dan lancar. Ini terlihat dimana warga masih kurang memahami tugas dan fungsi organisasi KSB yang dimiliki oleh instansi lokal (kelurahan) di daerah tersebut. Penulis melihat sebenarnya informasi dan sosialisasi yang pernah diberikan organisasi KSB disana memang sudah cukup baik, terbukti pada saat melakukan penyuluhan, simulasi dan sosialisasi, semua kegiatan tersebut telah didokumentasikan dengan baik oleh organisasi KSB. Hanya saja warga di kelurahan itu belum memahami tugas, fungsi dan tujuan dibentuknya KSB, karena organisasi KSB ini sengaja dibentuk oleh pemerintah/instansi lokal sebagai wakil pemerintah lokal di daerah rawan bencana saat pemerintah tidak dapat secara langsung turun ke lapangan. 


\section{UCAPAN TERIMAKASIH}

Dalam kesempatan ini penulis mengucapkan terimakasih kepada Lembaga Riset dan Teknologi Pendidikan Tinggi Kementerian Pendidikan dan Kebudayaan Republik Indonesia (RistekDikti Kemendikbud RI) sebagai pemberi dana Hibah Penelitian Dosen Pemula.

\section{DAFTAR PUSTAKA}

[1] J. Aridianto, D. Rohmat, and I. Setiawan, "The Arrangement of Model Instrument (Tentative) for Campus Evaluation with Earthquake and Tsunami Disaster Mitigation Insight," J. Phys. Conf. Ser., vol. 1387, no. 1, 2019, doi: $10.1088 / 1742-$ 6596/1387/1/012055.

[2] M. A. Marfai, A. Cahyadi, H. Fatchurohman, F. S. C. Rosaji, and Y. A. Wibowo, "Tsunami preparedness and environmental vulnerability analysis in Kukup Beach, Gunungkidul, Indonesia," IOP Conf. Ser. Earth Environ. Sci., vol. 256, no. 1, 2019, doi: $10.1088 / 1755-1315 / 256 / 1 / 012025$.

[3] R. Imani, U. D. Arman, and W. Boy, "Correlation between type of ground-based on b-value and the impact on buildings due to Sumatra earthquakes," MATEC Web Conf., vol. 02013, no. 229, 2018.

[4] J. C. Borrero, R. Weiss, E. A. Okal, R. Hidayat, D. Arcas, and V. V Titov, "The tsunami of 2007 September 12 , Bengkulu province , Sumatra, Indonesia: posttsunami field survey and numerical modelling," Geophys. J. Int, vol. 5, pp. 180-194, 2009, doi: $10.1111 / \mathrm{j} .1365-$

246X.2008.04058.x.

[5] D. Mardiatno, M. N. Malawani, D. N. Annisa, and D. Wacano,
"Review on tsunami risk reduction in Indonesia based on coastal and settlement typology," Indones. J. Geogr., vol. 49, no. 2, pp. 186-194, 2017, doi: 10.22146/ijg.28406.

[6] A. M. Nur, "Gempa Bumi, Tsunami dan Mitigasinya," Jurnal Geografi" vol. 7, no. $1,2010$.

[7] K. Sieh, P. Daly, E. E. McKinnon, J. E. Pilarczyk, H.Chiang, B. Horton, C. M. Rubin, C. Shen, N. Ismail, C. H. Vane, and R. M. Feener, "Penultimate Predesessors of The 2004 Indian Ocean Tsunami in Aceh, Sumatra: Stratigraphic, Archeological, and Historical Evidence ," J. Geophys. Res. Solid Earth, pp. 3782-3803, 2016, doi: 10.1002/2015JB012608.Received.

[8] F. Imamura, A. Muhari, E. Mas, M. H. Pradono, J. Post, and M. Sugimoto, "Tsunami disaster mitigation by integrating comprehensive countermeasures in Padang city, Indonesia," J. Disaster Res., vol. 7, no. 1, pp. 48-64, 2012.

[9] Undang-undang Nomor 24 Tahun 2007 "Tentang Penanggulangan Bencana," 2007.

[10] B. U. Isna, Madlazim, E. Hariyono, and N. Suprapto, "Development of OrSAEv Model Learning Materials to Strengthen the Characters of Tsunami Disaster Mitigation for Middle School Students (Preliminary Study)," J. Phys. Conf. Ser., vol. 1417, no. 1, 2019, doi: 10.1088/1742-6596/1417/1/012082.

[11] K. Anam and A. Mutholib, "Kesiapan Institusi Lokal dalam Menghadapi Bencana Tsunami : Studi Kasus Kelurahan Air Manis dan Kelurahan Purus , Kota Padang,"Jurnal Wilayah dan Lingkungan," vol. 6, no. April, pp. 15-29, 2018, doi: 10.14710/jwl.6.1.1529.

[12] M. Bilal Habibie and S. Sjafei, 
"Mitigasi Bencana Tsunami Melalui Pariwisata (Studi Kasus di Situs Tsunami Kapal PLTD Apung Banda Aceh)," Jurnal Ilmu Kebencanaan (JIKA) Pascasarj. Univ. Syiah Kuala, vol. 6, no. 2, p. 36, 2017.

[13] M. Hasan, M. M. Hasan, and B. J. Santosa, "Analisa Pola Bidang Sesar Pada Zona Subduksi di Wilayah Sumatera Barat dari Event Gempa Pada Tahun 2013," J. Sains dan Seni ITS, vol. 3, no. 1, pp. B11B14, 2014, doi: 10.12962/j23373520.v3i1.5717.

[14] Z. Alhadi and S. Sasmita, "Kesiapsiagaan Masyarakat Kota Padang dalam Menghadapi Resiko Bencana Gempa dan Tsunami Berbasis Kearifan Lokal (Studi Kesiapsiagaan Terhadap Resiko Bencana)," Jurnal Humanus, vol. XIII, no. 2, pp. 168-179, 2014. 